\title{
Recomendação da American Academy of Otolaryngology - Head and Neck Surgery Foundation (AAO-HNSF) sobre "rouquidão" (disfonia)
}

\author{
Comentado por: Mara Behlau' ${ }^{1}$, Gisele Oliveira²
}

Schwartz SR, Cohen SM, Dailey SH, Rosenfeld RM, Deutsch ES, Gillespie MB, Granieri E, et al. Clinical practice guideline: hoarseness (dysphonia). Otolaryngol Head Neck Surg. 2009;141:S1-S31.

O texto em questão é o primeiro documento nacional americano sobre rouquidão, produzido pela AAO-HNSF, uma das associações médicas mais antigas dos EUA, que representa 13 mil médicos e profissionais da saúde, especializados no diagnóstico e tratamento de distúrbios do ouvido, nariz, garganta e estruturas relacionadas da cabeça e pescoço. O parecer sobre "rouquidão" (disfonia) foi emitido em $02 \mathrm{de}$ setembro deste ano, com o objetivo de auxiliar profissionais da saúde a identificar e orientar pacientes com problemas de voz. A finalidade é atingir todos os médicos que possam atender, diagnosticar ou tratar um indivíduo com rouquidão. O paciente-alvo dessa recomendação é qualquer pessoa com rouquidão (disfonia), mas o texto não se aplica aos indivíduos com histórico de laringectomia parcial ou total, anomalias craniofaciais, insuficiência velofaríngea ou disartria.

Participaram da elaboração deste documento 24 especialistas das seguintes áreas: otorrinolaringologia, neurologia, fonoaudiologia, professores de voz, medicina de família, pneumologia, geriatria, medicina interna, pediatria, enfermagem, além de representantes dos consumidores. Os dois fonoaudiólogos convidados a contribuir com os trabalhos foram Joseph C. Stemple e Edie R. Hapner.

$\mathrm{Na}$ introdução do documento, os autores reforçam o conceito de rouquidão como um sintoma e disfonia como um diagnóstico. Destacam que há 20 milhões de roucos nos EUA e que um terço da população sofrerá um problema de voz em algum momento da vida, com uma prevalência $50 \%$ maior nas mulheres e maior incidência entre 8 e 14 anos, na terceira idade e nos profissionais da voz. A maior parte dos casos de rouquidão são quadros benignos, mas que exigem diagnóstico.

No texto, rouquidão (disfonia) é definida como um distúrbio caracterizado por alteração na qualidade vocal, freqüência

(1) Professora do Curso de Especialização em Voz do Centro de Estudos da Voz - CEV - São Paulo (SP), Brasil; Professora do Curso de Pós-graduação em Distúrbios da Comunicação Humana da Universidade Federal de São Paulo - UNIFESP - São Paulo (SP), Brasil.

(2) Pós-graduanda (Doutorado) do Curso de Pós-graduação em Distúrbios da Comunicação Humana da Universidade Federal de São Paulo - UNIFESP - São Paulo (SP), Brasil.

Endereço para correspondência: Mara Behlau. R. Machado Bittencourt, 361, $10^{\circ}$ andar, cj.1001, Vl. Mariana, São Paulo (SP), Brasil, CEP: 04044-001. E-mail: mbehlau@uol.com.br ou intensidade, ou esforço vocal que limita a comunicação ou causa impacto negativo na qualidade de vida relacionada à voz. Uma limitação na comunicação caracteriza-se por uma perda ou redução na habilidade de interagir vocalmente. Já, a limitação de qualidade de vida nos aspectos relacionados à voz é definida como um decréscimo autopercebido no seu estado físico, emocional, social ou econômico devido a uma disfunção vocal. Tais definições ressaltam o fato de que um problema de voz afeta os indivíduos de modo diverso.

A recomendação lista 11 aspectos importantes, acompanhados do tipo e grau de recomendação. O tipo de recomendação foi classificado em: recomendação forte, para as situações nas quais os médicos devem necessariamente seguir o indicado, a menos que exista razão impeditiva para tanto; recomendação, para as situações nas quais os médicos geralmente devem respeitar o que foi indicado, porém, ficando atentos às novas informações e às preferências dos pacientes; e recomendação opcional, em situações nas quais há flexibilidade de decisão e quando o paciente tem participação substancial neste processo. Nas situações de recomendação forte, os benefícios da abordagem recomendada sobrepassam claramente os riscos (ou os riscos claramente excedem os benefícios, nos casos de recomendação contrária); em tais situações, há excelente evidência científica para a proposta. Nas situações de recomendação, os benefícios excedem os riscos (ou os riscos excedem os benefícios, nos casos de recomendação contrária), porém, com menor qualidade de evidência científica. Finalmente, os casos de recomendação opcional refletem as situações nas quais a qualidade da evidência é pobre ou os estudos de alta qualidade mostraram poucas vantagens claras de uma abordagem sobre a outra.

A qualidade das evidências foi classificada de acordo com os seguintes graus de recomendação: A - estudos clínicos controlados, bem desenhados, com alocação casual de sujeitos ou estudos de diagnóstico realizados com uma população semelhante ao grupo-alvo da recomendação; B - estudos clínicos controlados, estudos de diagnóstico com pequenas limitações, ou evidência consistente e massiva advinda de estudos observacionais; C - estudos observacionais (casocontrole e coorte); D - opinião de especialistas, série de casos ou análises de princípios básicos (pesquisas in vitro ou 
estudos com animais); $\mathrm{X}$ - situações excepcionais, nas quais a validação de estudos não pode ser realizada e onde há uma clara preponderância de benefício sobre o risco.

Dos 11 aspectos selecionados, quatro são recomendações contrárias e uma opcional. Os autores ressaltam que este documento não tem o objetivo de ser a única fonte de orientação no manejo da rouquidão (disfonia), mas que foi desenhado a fim de auxiliar os médicos, oferecendo uma perspectiva baseada em evidências para o processo de decisão clínica. A recomendação não tem a intenção de substituir o julgamento clínico ou estabelecer um protocolo para todos os indivíduos com problemas de voz.

1. Diagnóstico: os médicos devem diagnosticar a rouquidão (disfonia) em um paciente com alteração de qualidade vocal, frequência, intensidade ou esforço vocal que impede a comunicação ou reduz a qualidade de vida nos aspectos relacionados à voz. Recomendação - Grau C. O objetivo desta recomendação é promover a conscientização de todos os médicos de que a rouquidão (disfonia) é uma condição que pode exigir intervenção ou investigação adicional. O diagnóstico proposto é baseado em critérios estritamente clínicos.

2. Investigação de fatores relacionados: os médicos devem investigar no paciente com rouquidão um ou mais dos seguintes fatores, a partir da história do problema e/ou avaliação física: cirurgias recentes envolvendo o pescoço ou o nervo laríngeo recorrente, intubação endotraqueal recente, radioterapia na região do pescoço, tabagismo ou uso profissional da voz. $R e$ comendação-Grau C. O termo "fatores relacionados" é usado no texto como referência aos detalhes eliciados pela anamnese ou exame físico do paciente que oferecem informações sobre a possibilidade de uma etiologia subjacente da disfonia que possa direcionar a conduta.

3a. Laringoscopia e rouquidão: os médicos podem fazer ou encaminhar para laringoscopia um paciente com rouquidão, em qualquer momento. Opcional - Grau $C$.

3b. Os médicos devem realizar ou encaminhar para laringoscopia um indivíduo com rouquidão há mais de três meses ou com rouquidão de qualquer duração quando há suspeita de uma causa séria. Recomendação - Grau C. Seu objetivo é ressaltar a importância de se visualizar a laringe, as pregas vocais, particularmente quando a rouquidão não melhora em um período de três meses (recomendação 3b), do momento em que pacientes com rouquidão persistente podem ter um quadro subjacente sério que não será diagnosticado a menos que se visualize a laringe. Isto não quer dizer que os pacientes devam esperar três meses para uma avaliação laringoscópica, já que uma avaliação precoce em alguns pacientes pode oferecer uma melhor conduta. Há várias técnicas para realizar laringoscopia e o documento não seleciona nenhum método como preferido.

4. Diagnóstico por imagem: os médicos não devem solicitar tomografia computadorizada (TC) ou ressonância magnética (RM) de pacientes com queixa primária de rouquidão antes de se visualizar a laringe. Recomendação contrária - Grau C. O objetivo é desencorajar o uso de diagnóstico por imagem como avaliação inicial e enfatizar que isto deve ser usado apenas para se avaliar uma alteração específica após a visualização da laringe. 5a. Medicação anti-refluxo e rouquidão: os médicos não devem prescrever drogas anti-refluxo para pacientes com rouquidão sem sinais ou sintomas de Doença do Refluxo Gastresofágico (DRGE). Recomendação contrária - Grau B.

5b. Os médicos podem prescrever drogas anti-refluxo para pacientes com rouquidão e sinais de laringite crônica. Opcional - Grau C. O objetivo principal desta recomendação é limitar o uso indiscriminado de drogas anti-refluxo como tratamento empírico para os casos de rouquidão sem evidência da doença do refluxo gastresofágico, do momento em que há efeitos adversos do uso das drogas e pouca evidência de seu benefício.

6. Corticosteróide: os médicos não devem prescrever corticosteróide oral rotineiramente para tratar rouquidão. Recomendação contrária - Grau B. Esteróides orais são comumente prescritos para rouquidão e laringite aguda apesar da gritante falta de dados científicos que justifiquem esta prática. O texto ressalta indicações particulares em que há indicação do uso de tais medicamentos como crupe recorrente com laringite em pacientes pediátricos e laringites alérgicas; além de alguma evidência de alívio rápido em laringite alérgica em artistas.

7. Terapia antimicrobiótica: os médicos não devem prescrever antibióticos rotineiramente para tratar rouquidão. Recomendação contrária forte-Grau A. A rouquidão por laringite aguda ou infecções das vias aéreas superiores geralmente não é causada por infecções bacterianas e, do momento em que antimicrobianos só são efetivos para tais condições, o uso empírico e rotineiro destas drogas não se justifica. Além das conseqüências negativas individuais do uso de antibióticos, há importantes implicações coletivas, como a possibilidade de se aumentar a resistência bacteriana. Situações específicas e raras como tuberculose laríngea, pacientes com transplante renal e indivíduos com o vírus da imunodeficiência humana (HIV) podem exigir antibióticos além de, evidentemente, casos de infecção bacteriana.

8a. Laringoscopia antes da terapia vocal: os médicos devem visualizar a laringe antes de prescrever terapia vocal, além de documentar e comunicar os resultados ao fonoaudiólogo. Recomendação - Grau C.

8b. Advogar a favor da terapia vocal: os médicos devem advogar a favor da terapia de voz para pacientes com uma rouquidão (disfonia) que reduz a qualidade de vida nos aspectos relacionados à voz. Recomendaçãoforte-Grau A. Terapia de voz é uma modalidade de tratamento bem estabelecida para alguns distúrbios vocais; contudo a terapia não deve ser iniciada antes do diagnóstico. A falta de visualização da laringe e do diagnóstico pode levar a uma terapia inadequada ou ao atraso do diagnóstico de uma alteração não tratável com fonoterapia. Além disso, as informações obtidas na laringoscopia podem auxiliar na configuração do regime de terapia optimal. O texto destaca afirmações semelhantes em documentos de duas sociedades de fonoaudiólogos, o desenvolvido pelo Royal College of Speech-Language Therapists - RCST, do Reino Unido, que recomenda que um paciente deve ser avaliado por um otorrinolaringologista ou simultaneamente por um otorrinolaringologista e fonoaudiólogo antes da terapia vocal, e a recomendação da American Speech-Language and Hearing Association - ASHA, dos Estados Unidos, de que todos os pacientes com distúrbios vocais sejam examinados por um 
médico, preferencialmente especialista da área da queixa do paciente. $\mathrm{O}$ texto reforça a importância de uma avaliação e tratamento multidisciplinar. A recomendação em seu item B reforça ainda que os médicos devem advogar a favor da terapia de voz promovendo a conscientização dos pacientes sobre a efetividade de tais intervenções. O tratamento interdisciplinar pode também incluir a contribuição de professores de canto, preparadores vocais e outras disciplinas médicas em conjunto com a terapia administrada por um fonoaudiólogo. A falta de conhecimento dos profissionais da saúde sobre a terapia de voz é considerada uma barreira para o encaminhamento e indicação, o que pode ser vencido por materiais educacionais sobre terapia de voz e suas indicações.

9. Cirurgia: os médicos devem advogar a favor da cirurgia como opção terapêutica para pacientes com rouquidão quando há suspeita de: 1) malignidade laríngea, 2) lesões benignas laríngeas, ou 3) insuficiência glótica. Recomendação - Grau $B$. Os médicos devem estar cientes de que a cirurgia pode ser indicada para certas condições que causam rouquidão, porém não é o tratamento primário para todos os pacientes com rouquidão e tem como alvo as condições específicas acima listadas. A cirurgia pode reduzir a rouquidão e melhorar a qualidade de vida em pacientes selecionados.

10. Toxina botulínica: os médicos devem prescrever ou encaminhar o paciente para um clínico que realize injeções de toxina botulínica para o tratamento de rouquidão causada por disfonia espasmódica. Recomendação - Grau B. A disfonia espasmódica é um distúrbio do sistema nervoso central que não é curado pela toxina botulínica, mas o paciente pode se beneficiar de um excelente controle sintomatológico por um período de três a seis meses, com as injeções de toxina. Embora no presente momento este tratamento não seja aprovado pelo Food and Drug Administration (FDA), há evidências importantes que apóiam o seu uso para os casos de disfonia espasmódica de adução.

11. Prevenção: os clínicos podem educar ou aconselhar pacientes com rouquidão sobre medidas preventivas ou de controle de problemas vocais. Opcional - Grau C. O risco de disfonia pode ser reduzido por medidas preventivas como hidratação, evitar irritantes (fumaça de cigarro primária ou passiva, químicos, inalantes e poluição), treinamento vocal e amplificação de voz, embora os estudos atualmente disponíveis sejam de qualidade e objetivo limitado.

A disseminação do presente documento entre os profissionais da saúde, convênios médicos e pacientes em geral pode seguramente produzir melhoria nas condições de diagnóstico e tratamento dos problemas de voz, além de incentivar programas de prevenção das disfonias. A inclusão de uma recomendação a favor da terapia vocal é uma conquista fonoaudiológica sobre o reconhecimento dos efeitos positivos dessa modalidade de tratamento, por outros profissionais da área da saúde. 